\title{
Performance-based Optimal Design of Cantilever Retaining Walls
}

\author{
Mohsen Kalateh-Ahani ${ }^{1 *}$, Arman Sarani ${ }^{2}$ \\ 1 Department of Civil Engineering, \\ University of Torbat Heydarieh, \\ Torbat Heydarieh, Iran \\ 2 Department of Civil Engineering, \\ Islamic Azad University, Torbat Heydarieh Branch, \\ Torbat Heydarieh, Iran \\ *Corresponding author, e-mail: m.kalatehahani@torbath.ac.ir
}

Received: 28 September 2018, Accepted: 08 February 2019, Published online: 11 April 2019

\begin{abstract}
Modern buildings should provide some degree of safety against severe earthquakes. However, it is not economically feasible to construct buildings that withstand extreme loads without avoiding damage. In performance-based design, structural engineers and owners work together to achieve the best possible balance between construction cost and seismic performance. In this study, by employing a metaheuristic optimization, we have tried to extend the concept of performance-based design to retaining wall structures. According to the AASHTO LRFD Bridge Design Specifications, permanent displacement of retaining structures are tolerable, as long as the movement does not lead to unacceptable damage to the structure or facilities located in or near the moving earth. The decision on performance expectations needs to be made by owners with structural engineers providing a realistic assessment of the cost of designing to avoid the movement. To make this assessment possible, we developed a multi-objective optimization framework for simultaneous minimization of the construction cost and the permanent displacement of cantilever retaining walls. The effectiveness of the proposed framework was evaluated in the design of a typical cantilever retaining wall of 8 meters in height, once with both a toe and heel slab and once with either of them. The results indicated that obtaining the Pareto front of optimal solutions for these objectives, provides useful information that helps owners to select a solution that is the most economical in a trade-off between the construction cost and performance expectation.
\end{abstract}

\section{Keywords}

retaining walls, performance-based design, optimization, construction cost, permanent displacement

\section{Introduction}

Retaining wall is a structure designed and constructed to resist the lateral pressure of soil when there is a desired change in ground elevation that exceeds the angle of repose. Gravity, semi-gravity and cantilever retaining walls are the most common types of concrete retaining walls. The stability of gravity walls depends on their weight and any soil located on the stem and the base. Cantilever walls include reinforcing steel to minimize the thickness of the wall. Semi-gravity walls are a blend of the gravity and the cantilever type, without requiring extensive reinforcement [1].

Given the direct relation between the amount of concrete and reinforcing steel used and the total construction cost, performing size optimization for retaining walls is of particular importance. Thus in recent decades, many studies have been conducted to provide cost-efficient designs. Saribas and Erbatur [2] applied a nonlinear programming method to solve a seven design variables problem, in which the weight of reinforced concrete retaining walls was considered as a objective function. Ceranic et al. [3] employed Simulated Annealing (SA) to minimize the construction cost of cantilever retaining walls. Yepes et al. [4] conducted a parametric study using SA on optimum design of cantilever retaining walls, formulating the problem containing 20 design variables. Particle Swarm Optimization (PSO) algorithm was used by Ahmadi-Nedushan and Varaee [5] for separate weight and cost optimization of reinforced concrete 
retaining walls. An improved version of Harmony Search (HS) algorithm was proposed by Kaveh and ShakouriMahmud-Abadi [6] for optimum cost design of cantilever retaining walls. A procedure was developed by Camp and Akin [7] for designing low-cost cantilever retaining walls using Big Bang-Big Crunch optimization (BB-BC). Talatahari and Sheikholeslami [8] enhanced Charged System Search (CSS) algorithm for optimization of gravity and cantilever retaining walls. Kaveh and Soleimani [9] employed Colliding Body Optimization (CBO) and Democratic Particle Swarm Optimization (DPCO) for minimization of the cost of material used in reinforced concrete retaining walls. Kaveh and Farhoudi [10] demonstrated the superiority of Dolphin Echolocation Optimization (DEO) over the previously used algorithms in the cost optimization of cantilever retaining walls.

Undoubtedly, the economic objective is the main concern of owners and structural engineers at the beginning of a construction project. However, it could not address all the concerns for the whole expected service duration of a structure. For example, in reinforced concrete structures, bar congestion complicates steel placement, hinders concrete placement and as a result leads to improper consolidation of concrete around bars affecting the integrity of the structure. Kaveh et al. [11] studied the importance of high constructability in the optimal design of cantilever retaining walls. They developed a multi-objective genetic algorithm considering minimization of the construction cost and the reinforcing bar congestion as the two objectives of the optimization problem.

Significant earthquakes can cause serious damage in structures which may lead to extensive consequences in terms of human losses (deaths and serious injuries), direct economic losses (building repair or replacement cost), and indirect losses (repair time and downtime). In performance-based design, structural engineers communicate seismic performance levels to owners. Therefore, owners could identify a specific performance level for serviceability and strength; the new building is then designed to ensure compliance with the agreed level. By choosing an appropriate performance level, based on the location and function of the building, the probable seismic damage and the resulting losses from potential future earthquakes would be limited and under control [12].

For retaining structures, the movement of the structure during earthquakes may cause severe damage to the wall or the adjoining structures. A comprehensive study on retaining wall displacements during ground motions and the subsequent damages has been reported by Lai [13] and Li et al. [14]. For instance, arterial roads that are high-capacity urban routes intended for through traffic in emergency situations, should be designed such that after significant earthquakes their function as a transport corridor is served and the potential damage does not undermine their strategic role. Excessive movements of the retaining walls, where they directly support roads as bridge abutments or in highway structures, have a negative impact on the efficiency, safety, and function of the arterial roads. Limiting the permanent displacement of retaining walls, not only ensures road safety and avoids traffic disruption, but also reduces the probable economic losses [15].

The conventional approach to design retaining walls has two basic requirements: "external stability" which means the structure as a solid should retain the backfill mass with respect to geotechnical requirements, and "internal stability" which is ensured by providing sufficient resistance against bending moments and shear forces as determined by concrete codes [1]. The existing AASHTO specifications use an empirical equation based on Newmark sliding block analyses to compute wall displacements. In most cases, limiting displacements under seismic loading needs larger capacity in the wall than required to satisfy the internal and external stability criteria. Consequently, an optimal solution for minimizing construction cost is not simultaneously optimal for minimizing wall displacement. In the optimization literature, these objective functions are said to be conflicting, and there exists a number of Pareto optimal solutions instead of one single solution. A solution is called Pareto optimal if none of the objective functions can be further improved without degrading the other objective functions. The set of all Pareto optimal solutions forms a surface called a Pareto front [16].

This paper presents a multi-objective framework for the optimal design of cantilever retaining walls, considering construction cost and permanent wall displacement as two objective functions to be minimized at the same time. The goal is to find a representative set of Pareto optimal solutions to help structural engineers communicate with owners and demonstrate the nature of trade-offs between the two conflicting objectives. The non-dominated sorting genetic algorithm (NSGA-II) [17] is used as an optimizer to search the Pareto optimal solutions. Visualizing the Pareto front assists owners in selecting an optimal solution that ensures the expected performance within the budget constraints.

\section{Optimal design problem}

The present optimization problem deals with a bi-objective optimization of the construction cost and the permanent displacement of cantilever retaining walls, expressed by: 
$\{\operatorname{minimize} F(x)=(\operatorname{Cos} t(x), \operatorname{PermDisp}(x))$

$$
g_{i}(x) \leq 0 \quad i=1,2, \ldots
$$

where $x=\left\{x_{1}, x_{2}, \ldots, x_{n}\right\}$ are the design variables and $g(x)$ represents all the constraints and requirements must be satisfied by the design code. The first objective function, as defined by Eq. (2), is the construction cost, where $p$ is the unit prices, $m$ measures the items the construction procedure of a common cantilever retaining wall is divided into, and $r$ is the total number of these items. The cost function includes materials cost (concrete and steel) and the cost of all construction items required to evaluate the total cost of a wall per meter of length, e.g., earth removal, backfill, formwork, concrete placing and rebar installation. Table 1 lists the unit prices considered for the materials and the construction items, which are provided by a local Iranian contractor in road construction in September 2017.

$\operatorname{Cost}(x)=\sum p_{i} \times m_{i}$.

Cost-based optimization of retaining walls generally provides optimal solutions that have lower construction cost than others among all possible scenarios. However, the basic goal of structural engineers is to design structures that are both economical and safe against probable earthquakes, which conflict with each other [18]. As explained earlier, permanent displacement of a retaining wall is of particular importance to keep the safety of using the wall as a part of a bridge or a highway structure. The second objective function PermDisp $(x)$ computes the permanent displacement of cantilever retaining walls under the design earthquake. The calculation procedure is described in details in Sect. 4.4.

Table 1 Unit prices for materials and construction items.

\begin{tabular}{lc}
\hline Item & Price (US\$) \\
\hline Cubic meter of earth removal & 11.41 \\
Cubic meter of backfill & 38.1 \\
Kilogram of steel - Grade $40(275.79 \mathrm{MPa}) *$ & 1.54 \\
Kilogram of steel - Grade $60(413.69 \mathrm{MPa})$ & 1.51 \\
Cubic meter of concrete - C20 (20 MPa) * & 94.45 \\
Cubic meter of concrete - C25 $(25 \mathrm{MPa})$ & 99.49 \\
Cubic meter of concrete - C30 $(30 \mathrm{MPa})$ & 104.51 \\
Cubic meter of concrete - C35 $(35 \mathrm{MPa})$ & 108.53 \\
Cubic meter of concrete - C40 $(40 \mathrm{MPa})$ & 118.05 \\
Square meter of foundation formwork & 36.82 \\
Square meter of stem formwork & 37.08 \\
Cubic meter of concrete placing & 35.48 \\
Kilogram of rebar installation & 0.98 \\
\hline
\end{tabular}

* For steel materials indicates the specified yield strength and for concrete materials indicates the specified compressive strength.

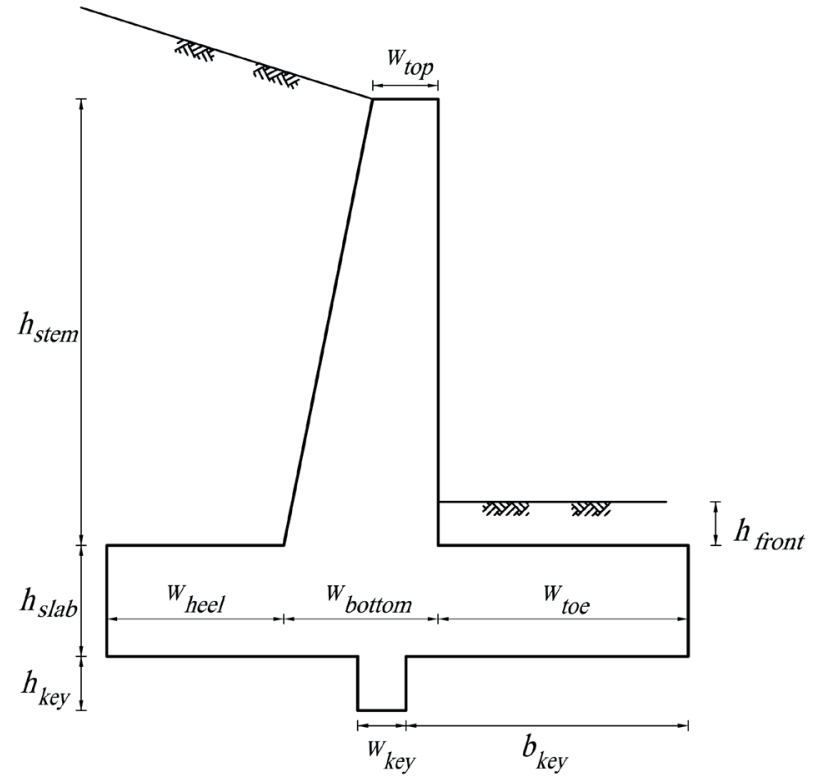

(a) Schematic view

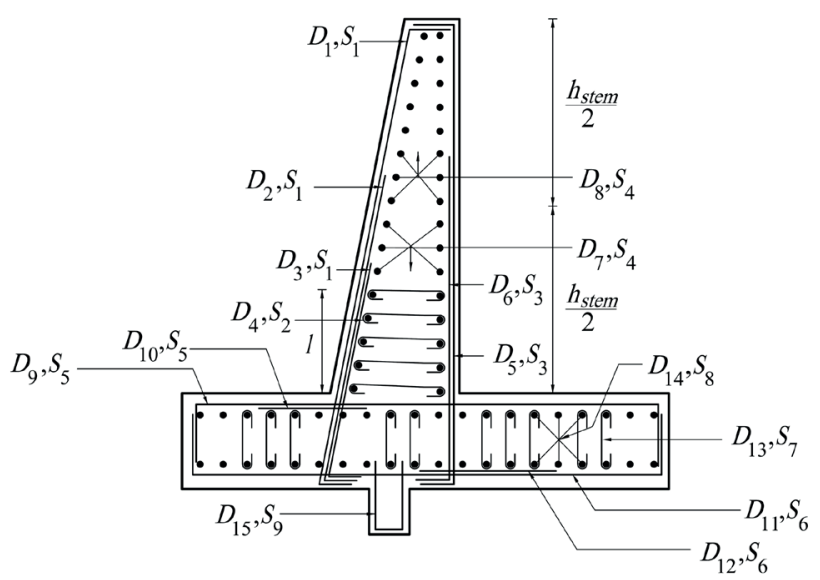

(b) Reinforcement configuration

Fig. 1 Analytical model of cantilever retaining walls

\section{Structural modeling}

The analytical model used in this study to represent cantilever retaining walls comprises of 9 design variables, which define the geometry of the wall and the strength grade of the concrete materials. Fig. 1(a) shows a schematic view of this model. The design variables include seven geometric variables, i.e., the bottom thickness of the stem $w_{\text {bottom }}$, the thickness of the base slab $h_{\text {slab }}$, the length of the heel $w_{\text {heel }}$, the length of the toe $w_{\text {toe }}$, the thickness of the shear key $w_{k e y}$, the depth of the shear key $h_{k e y}$, and the location of the shear key $b_{k e y}$. The top thickness of the stem $w_{\text {top }}$ is assumed to be constant. As well, two separate variables represent the grade of concrete used: one for the stem and one for the base slab. The strength of a concrete mix is measured in grades that the grade of concrete means the concrete compression resistance after 28 days $\left(f_{c}\right)$. 
Since reinforcement costs directly impacts on the total construction cost of cantilever retaining walls, it should be included in the cost function. In the proposed framework, the seven geometric and the two grade variables are only evolved by the optimization algorithm and the reinforcement setup for each solution should be calculated through another procedure. Reinforcement requirements are determined in accordance with ACI-318 [19]. Three types of reinforcing bars are required for cantilever retaining walls: longitudinal bending reinforcement, transverse shear reinforcement, and secondary reinforcement to avoid shrinkage and thermal effects.

Reinforcement configuration of the analytical model is shown in Fig. 1(b). As indicated in this figure, different reinforcement sets are considered in different parts of the stem and the base slab. Each set is identified by two parameters, one indicating the diameter of the reinforcing bars $(D)$, and the other, the spacing between them $(S)$. In total, 15 parameters represent the bars' diameter, and 11 parameters represent the spacings. The difference in the number of parameters assigned to the diameters and the spacings is for the attention to the ease of reinforcing bar installation; since it is desirable that the extra and the existing bars are bundled together. In Fig. 1(b), the reinforcement sets that have the same spacing are separated by an identical number. For more detailed information about the reinforcement configuration and the numbers assigned to each set, refer to Kaveh et al. [10]. To provide a more precise cost evaluation of the reinforcement setup, both the development and anchorage length are added to the required length of the longitudinal bars wherever needed, in accordance with ACI-318 [19].

\section{Structural evaluation}

In the proposed framework, when a solution is generated and the corresponding structure is modeled, results from the structural analysis of the new structure are checked against a set of predefined constraints. Structures that meet all the constraints are labeled feasible solutions, and those that do not, are labeled unfeasible ones, which are discarded.

There are two types of constraints in the design procedure of a common cantilever retaining wall. Firstly, the structure as a whole is checked for external stability, i.e., it is examined for possible "overturning", "sliding", and "bearing" failures. The purpose of the external stability check is to ensure that the size of the wall and the implied geotechnical capacity is sufficient. Secondly, each component of the wall is checked for internal stability and the required reinforcing bars of each component is verified. The purpose of the internal stability check is to ensure that structural components function properly under the increased dynamic loads from future earthquakes [15].

AASHTO LRFD Bridge Design Specifications [20] uses a number of partial safety factors on loads and resistances for the design of bridge structures and components. Each factor relates to a limit state. Four limit states are specified in the LRFD specifications: service limit state; fatigue and fracture limit state; strength limit state; extreme event limit state. Limit states are expressed by functional requirements such as the limiting deformation, stress or cracks, or by safety requirements such as the maximum strength. The design shall be investigated for any combination of the factored forces that may produce the most severe condition of loading.

Many of the AASHTO LRFD load combinations need not be considered in the design of conventional retaining walls. According to NCHRP-12-70 [21], Load combinations Strength I and Extreme Event I are controlling the design process. Two sets of load factors for Strength I load combinations are used to check the stability. One set induces the maximum eccentricity on the foundation, while the other set induces the maximum bearing pressure. These load combinations are differentiated by Strength I-a and Strength I-b designations. Load and resistance factors for these two load combinations and for Extreme Event I are listed in Table 2.

In what follows, a brief description of determining the external stability of retaining walls is provided. For more details, refer to AASHTO LRFD [20] and Das [1]. Checks for the internal stability can be found in any textbook on reinforced concrete.

The seismic behavior of retaining walls entirely depends on the total lateral earth pressure that develops during earthquake ground movements. This pressure includes both the static gravitational exists before an earthquake occurs, and the transient dynamic pressure induced by an earthquake. AASHTO LRFD [20] specifies that for the estimation of the seismic earth pressure either the Mononobe-Okabe (M-O) method or the Generalized Limit pressure that Equilibrium (GLE) method could be used. The implementation of the $\mathrm{M}-\mathrm{O}$ method is acceptable only where the wall is free to move enough in order to mobilize the active pressure conditions, and the backfill is cohesionless and unsaturated. In this study, despite the limitations, the M-O method that is frequently used by most structural engineers, is adopted for the calculation of the seismic earth pressures. 
Table 2 Load and resistance factors

\begin{tabular}{|c|c|c|c|}
\hline \multirow{2}{*}{ Load } & \multicolumn{3}{|c|}{ Load factor } \\
\hline & Strength I-a & Strength I-b & Extreme Event I \\
\hline Active earth pressure, horizontal component & 1.50 & 0.90 & 1.00 \\
\hline Active earth pressure, vertical component & 1.00 & 1.35 & 1.00 \\
\hline Vertical soil pressure & 1.00 & 1.35 & 1.00 \\
\hline Dead load of structural component & 0.90 & 1.25 & 1.00 \\
\hline \multirow{2}{*}{ Sliding } & \multicolumn{3}{|c|}{ Resistance factor } \\
\hline & Strength I-a & Strength I-b & Extreme Event I \\
\hline Passive earth pressure, horizontal component & 0.50 & 0.50 & 1.00 \\
\hline Passive earth pressure, vertical component & 0.50 & 0.50 & 1.00 \\
\hline Cohesion, $c$ & 0.80 & 0.80 & 1.00 \\
\hline \multirow{2}{*}{ Bearing capacity } & \multicolumn{3}{|c|}{ Resistance factor } \\
\hline & Strength I-a & Strength I-b & Extreme Event I \\
\hline Cohesion, $c$ & 0.60 & 0.60 & 1.00 \\
\hline Friction angle of soil, $\varphi$ & 0.55 & 0.55 & 1.00 \\
\hline
\end{tabular}

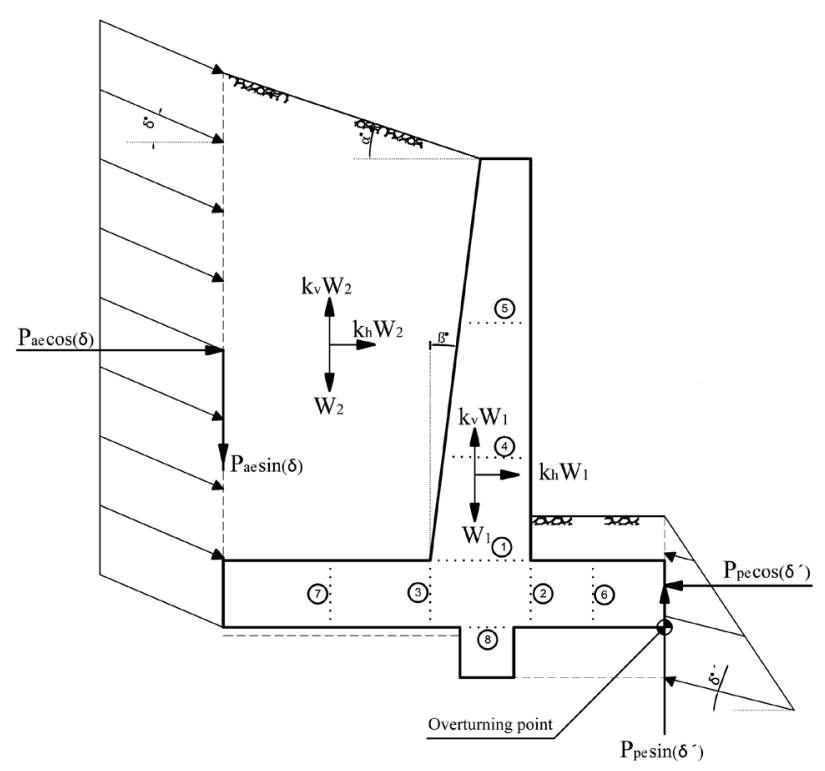

Fig. 2 Main forces in the M-O method

\subsection{Mononobe-Okabe method}

The M-O method is a pseudo-static approach, taking into account horizontal and vertical inertial forces acting on soil masses and retaining walls. Fig. 2 demonstrates the key forces in the M-O method: total weight of wall $\left(W_{1}\right)$, weight of backfill $\left(W_{2}\right)$, weight of soil on the toe $\left(W_{3}\right)$, surcharge load $(\omega)$, inertial forces in the horizontal direction $\left(k_{h} W_{1}, k_{h} W_{2}\right)$ and in the vertical direction $\left(k_{v} W_{1}, k_{v} W_{2}\right)$, and finally seismic active and passive earth pressure $\left(P_{A E}, P_{P E}\right)$. The seismic active and passive earth pressure are computed as follows [20]:

$$
\begin{aligned}
& P_{A E, P E}=\frac{1}{2} \gamma_{\text {soil }} H^{2}\left(1-k_{v}\right) K_{A E}, \\
& K_{A E, P E}=\frac{\operatorname{Cos}^{2}(\varphi \mp \beta-\theta)}{\psi \operatorname{Cos}^{2}(\beta) \operatorname{Cos}(\theta) \operatorname{Cos}(\delta \pm \beta+\theta)} \\
& \psi=\left[1 \pm \sqrt{\frac{\operatorname{Sin}(\varphi+\delta) \times \operatorname{Sin}(\varphi-\theta \mp i)}{\operatorname{Cos}(\delta \mp \beta+\theta) \times \operatorname{Cos}(i-\beta)}}\right]^{2}
\end{aligned}
$$

where

$H=$ height of backfill;

$\phi=$ friction angle of soil;

$\beta=$ slope of rear face of stem (negative in value);

$\delta=$ wall backfill interface friction angle;

$i=$ backfill slope angle with respect to the horizontal;

$k_{h}=$ vertical seismic acceleration coefficient;

$k_{v}=$ horizontal seismic acceleration coefficient; and

$\theta=\arctan \left(k_{h} /\left(1-k_{v}\right)\right.$.

NCHRP-12-70 [21] recommends $k_{h}=F_{g p a}$ PGA and $k_{v}=0$ are appropriate to use with the $\mathrm{M}-\mathrm{O}$ method. PGA is the peak ground acceleration coefficient and $F_{g p a}$ is a site factor for the PGA.

\subsection{External stability}

As described above, three constraints check the external stability of a wall for possible overall failures. AASHTO LRFD [20] recommends using limiting equilibrium methods of analysis for evaluation of the external stability. Eccentricity constraint controls whether the resisting 
moments are greater than the overturning moments to prevent rotation of a wall about the toe or not. The resisting moments result mainly from the self-weight of structure and the weight of backfill, whereas the main source of overturning moments is the seismic active earth pressure and the horizontal inertial forces. This constraint is as follows [20]:

$e=\frac{w}{2}-\frac{\sum M_{R}-\sum M_{O}}{\sum F_{V}}$,

where

$e=$ eccentricity of resultant force from the centerline of foundation;

$w=$ width of foundation;

$\sum M_{O}=$ sum of moments of factored horizontal forces tending to overturn about overturning point;

$\sum M_{R}=$ sum of moments of factored vertical forces tending to resist overturning; and

$\sum F_{V}=$ sum of factored vertical forces.

According to AASHTO LRFD [20], a satisfactory design requires the wall to satisfy the eccentricity criteria as follows:

- $e / w \leq 1 / 6$ for Strength I load combination on soil;

- $e / w \leq 1 / 4$ for Strength I load combination on rock;

- $e / w \leq 1 / 3$ for Extreme event I load combination.

Sliding failure occurs if the force effects due to the horizontal component of loads exceeds the more critical of either the factored shear resistance of the soils or the factored shear resistance at the interface between the soil and the foundation. Sliding constraint may be taken as [20]:

$$
\frac{\sum F_{R}}{\sum F_{D}}>1
$$

where

$\sum F_{R}=$ sum of factored resisting forces; and

$\sum F_{D}=$ sum of factored driving forces.

In order to increase the sliding resistance of retaining walls, other than providing a large self-weight or a large retained soil mass, shear keys can be installed at the base. The main purpose of the installation of shear keys is to increase the extra passive resistance developed by the height of shear keys [1].

Lastly, the bearing resistance of the foundation soil must be large enough to resist the pressures transmitted to the soil by the base slab. The bearing constraint, where the wall is supported by a soil foundation, is expressed as [20]:

$$
\frac{q_{R}}{\sigma_{V}}>1
$$

$\sigma_{V}=\frac{\sum F_{V}}{w-2 e}$

$q_{R}=\varphi_{b} q_{n}$

where

$q_{R}=$ factored bearing resistance;

$\varphi_{b}=$ bearing resistance factor;

$q_{n}=$ nominal bearing resistance; and

$\sigma_{V}=$ vertical bearing stress.

The nominal bearing resistance should be estimated using accepted soil mechanics theories based on measured soil parameters. AASHTO refers to Munfakh et al. [22] in order to calculate the nominal bearing resistance. In this study, we applied the detailed procedure as specified in Article 10.6.3.1 of AASHTO LRFD [20].

\subsection{Internal stability}

The internal stability deals with the flexural and shear strength of the structural system. The strength calculations of retaining walls are performed per linear meter for the ultimate flexure and shear at different sections of the stem and the base slab in accordance with ACI-318 [19]. These sections are identified in Fig. 2 with dotted lines. Although critical sections for bending and shear is at the bottom of the stem and in the base are taken at the face and back of the stem (Section 1, 2 and 3 in Fig. 2), the required reinforcing bars at these sections do not need to be extended along the whole length of the stem, the heel or the toe. Therefore, in the analytical model used in this study four extra sections - two sections in the stem and one section in the heel and in the toe - are taken which are denoted by number 4, 5, 6 and 7 in Fig. 2.

For strength calculations, AASHTO LRFD [20] specifies that lateral loads acting on a wall - including the seismic active earth pressure and the horizontal inertial forces - shall be the same earth pressures used for the external stability calculations. Whenever the flexural and shear capacity are verified at each section, it must be checked whether the secondary reinforcement of the stem and the base comply with the minimum requirements of provisions for the thermal and shrinkage effect or not.

\subsection{Permanent displacement}

About the effects of wall sliding during ground motions, in the displacement-based design approach of AASHTO LRFD [20], the Newmark sliding block analysis is used to compute displacements when ground accelerations exceed the yield acceleration for a wall-backfill system. 
The yield acceleration is a horizontal acceleration corresponds to the acceleration level for a sliding factor of safety of 1.0 , i.e.

$$
F S_{\text {slidig }}=\frac{b_{k e y} \sigma_{V} \tan (\varphi)+\left(w-2 e-b_{k e y}\right) \tan \left(\delta^{\prime}\right)}{k_{h}\left(W_{1}+W_{2}\right)+P_{A E}},
$$

assume $F S_{\text {sliding }}=1$, then

$k_{y}=\frac{b_{k e y} \sigma_{V} \tan (\varphi)+\left(w-2 e-b_{k e y}\right) \tan \left(\delta^{\prime}\right)-P_{A E}}{W_{1}+W_{2}}$,

where

$k_{y}=$ yield acceleration; and

$\delta^{\prime}=$ friction angle between soil and foundation $\left(\delta^{\prime}<\phi\right)$.

Various researchers have proposed different relationships for predicting the permanent displacement of earth structures subjected to seismic loadings. Based on regression analyses, NCHRP-611 [15] recommends that the permanent displacement, for soil sites, can be estimated by:

$$
\begin{aligned}
& \log (d)=-1.51-0.74 \log \left(\frac{k_{y}}{k_{\text {max }}}\right)+3.27 \log \left(1-\frac{k_{y}}{k_{\text {max }}}\right) \\
& -0.80 \log \left(k_{\text {max }}\right)+1.59 \log (\mathrm{PGV}),
\end{aligned}
$$

where

$d=$ permanent displacement (in inches);

$k_{\max }=$ maximum seismic acceleration coefficient; and $\mathrm{PGV}=$ peak ground velocity;

The peak ground velocity is determined using PGV = $55 F_{v} S_{1}(\mathrm{in} / \mathrm{sec})$, where $S_{1}$ is the spectral acceleration at 1 second and $F_{v}$ is the site class adjustment.

\subsection{Acceptable displacements for retaining walls}

An important question in any approach that involves permanent deformations is the amount that is acceptable. The specifications and commentaries to the NCHRP-12-70 [21] leave this decision to owners, who must weigh a number of factors in reaching this decision. To make the decision possible, NCHRP provide a detailed strategy for owners to use when determining the amount of permanent displacements that is acceptable for certain retaining wall types during seismic events.

Permanent displacements are generally associated with sliding and rotation of the retaining walls, where the entire soil mass with the wall moves. This movement could affect the internal and external stability of the retaining walls and induce structural damage or collapse. The factors that should be considered when deciding on acceptable levels of the permanent displacement, range from implications of the movement to the wall geometry and the type of soil [15].
When considering these factors, owners should evaluate both the relative consequences of movement and, as appropriate, the cost of designing to avoid the movement. In other words, expecting higher performance from a wall would cost owners a larger initial investment. This is where optimization comes into play. Some of the main factors are as follows [15]:

- Walls in urban locations usually can tolerate less movement than walls located in the countryside. Part of this relates to the effects of wall movement on utilities, sidewalks, pavements and other nearby facilities, and part relates to aesthetics;

- Walls that support a heavily traveled roadway should usually be designed for smaller displacements than walls that are part of a less traveled roadway. Roadways with heavy use will result in significant traffic and economic disruption if they are out of service for even a few hours;

- Generally, shorter walls can tolerate more permanent displacement than taller walls;

- Walls that are designed with a batter are better able to handle permanent movement than walls with a vertical face;

- Displacement of walls located on stiff clays or dense cohesionless soils will likely have higher reliability than for softer soils.

As summarized above, many factors must be considered when deciding on the acceptable level of displacement for a retaining wall. These factors make the development of a simple strategy for establishing the permanent displacement difficult. NCHRP-12-70 [21] specifies as soon as the displacement exceeds 1 to 2 inches, owners should perform a comprehensive review of the possible consequences of the movement to the wall and facilities located in proximity to the wall. In this study, 1.5 inches (3.81 centimeters), as an average value, is supposed to be an upper bound for the acceptable range.

In the proposed framework, whenever Pareto optimal solutions are provided by the NSGA-II optimizer, each solution on the Pareto front is labeled a high- or low-risk solution, regarding the performance level of the solution. Solutions with acceptable permanent displacement are considered to have a low-risk, and the others a high-risk performance level. The former means the post-earthquake damage state in which very limited structural damage has occurred. The wall retains nearly all of its pre-earthquake strength and stiffness. The risk of life-threatening injury as a result of structural damage is very low, although some 
minor structural repairs may be appropriate. On the other hand, the latter means the post-earthquake damage state in which significant damage to the wall has occurred. Some structural elements and components are severely damaged. Injuries may occur during the earthquake. The general descriptions of the both damage states are in accordance with the specifications of NCHRP-12-70 [21], Appendix Ax, in which a strategy is identified that can be followed by owners when establishing performance levels for a rigid or semi-rigid retaining wall.

\section{Optimization algorithm: NSGA-II}

The detailed implementation procedure of NSGA-II algorithm can be found in [23]; in what follows, a general description of this algorithm is presented. Once a population is initialized, two fitness values are assigned to each individual. First, NSGA-II uses a "non-dominated sorting" algorithm for fitness assignment in which all individuals that are not dominated by any other individual are assigned front number 1; all individuals only dominated by the individuals in front number 1 are assigned front number 2 , and so on. Then, a value called "crowding distance" is calculated for each individual; it is a measure of how close an individual is to its neighbors. A higher fitness value is assigned to individuals located on the sparsely populated part of a front [23].

Parent selection is made using a "binary tournament selection" based on the assigned fitness values. This selects, between two random individuals, the one with the lowest front number, if the two individuals are from different fronts. When the individuals are from the same front, the individual with the highest crowding distance is selected. Then, the selected individuals generate offsprings using genetic operators. The genetic operators applied in this study are differential evolution (DE) operator for crossover and polynomial mutation operator (for details, see [23] and [16]).

In the next step, the offspring population is combined with the current generation's population and forms an intermediate population. Then, "replacement" is performed to set the individuals of the next generation. Since all previous and current best individuals are included, elitism is ensured. According to the replacement policy, the intermediate population is sorted based on the non-domination rule, then the new generation is filled with fronts, one after another until the population size exceeds the given size. If by adding all the individuals from the $i$ th front, the population size exceeds, then individuals in the $i$ th front are selected based on their crowding distance in descending order until the population is formed. This process is repeated to generate the subsequent generations until the "termination criterion" is met [23].

To handle the given constraints, a relatively simple scheme is adopted. Whenever two individuals are compared for sorting population in different fronts, first, they are checked for constraint violation. If both are feasible, the non-domination rule is directly applied to decide the winner. If one is feasible and the other is infeasible, the feasible dominates. If both are infeasible, the one with the lowest amount of constraint violation dominates the other. This is the approach developed by [23] and [23] for constraint handling.

\section{The proposed framework}

Now, all of the components introduced in the previous sections are incorporated in a simple framework, which makes it possible to solve the optimal design problem. The main procedure that is based on the NSGA-II algorithm, is as follows:

\section{Main procedure \{}

1. Set parameters.

1.1. Set NSGA-II user-defined parameters, e.g., population size, number of parents, number of offsprings, number of generations, etc.

1.2. Set input parameters required for structural modeling, analysis and design process.

2. Initialize a population.

2.1. Generate a random individual.

2.2. Evaluate the new individual.

3 . Sort the initial population based on the non-domination rule and calculate crowding distances.

4. Select parents using the binary tournament selection.

5. Generate offsprings by performing genetic operators.

5.1. Generate a new individual.

5.2. Evaluate the new individual.

6 . Form an intermediate population by merging the current population with the offsprings.

7. Sort the intermediate population based on the non-domination rule and calculate crowding distances.

8. Perform replacement on the intermediate population to determine a new population.

9. Stop if the termination criterion is met, otherwise go to step 4 .

;

Evaluate \{

1. Construct a corresponding structural model for the new individual. 
2. Perform structural evaluation.

2.1. Check external stability.

2.2. Check internal stability.

3. Calculate constraint violation.

4. Calculate objective functions.

4.1. Compute construction cost.

4.2. Compute permanent displacement.

5. Determine performance level of the new individual. \}.

\section{Case study}

The proposed framework was implemented in MATLAB ${ }^{\circledR}$ [25] and a computer program was developed for the optimal design of cantilever retaining walls. In what follows, the design of a typical wall of 8 meters in height and 10 meters in length is investigated as a test example in three different cases: (I) with both a toe and a heel slab, (II) without a heel slab, and (III) without a toe slab. The detailed description of the example is provided for case I, whereas the differences are only noticed in cases II and III.

\subsection{Case I: a wall with both a toe and a heel slab}

The test structure is located in Los Angeles, California, and the type of soil profile is assumed to be D (stiff soil) at the site. Table 3 gives a list of parameters used in this example and their corresponding values. The ground motion parameters were selected using U.S. Seismic Design Maps [26].

Table 3 Parameters of the test example

\begin{tabular}{lc}
\hline Parameter & Value \\
\hline Height of backfill $(H)$ & $8 \mathrm{~m}$ \\
Top thickness of the stem $\left(w_{\text {top }}\right)$ & $0.5 \mathrm{~m}$ \\
Height of soil on the toe $\left(h_{\text {front }}\right)$ & $0.8 \mathrm{~m}$ \\
Surcharge load $(\omega)$ & $1000 \mathrm{~kg} / \mathrm{m}^{2}$ \\
Backfill slope $(i)$ & $0^{\circ}$ \\
Friction angle of soil $(\phi)$ & $30^{\circ}$ \\
Wall backfill interface friction angle $(\delta)$ & $0^{\circ}$ \\
Friction angle between soil and foundation $\left(\delta^{\prime}\right)$ & $24^{\circ}$ \\
Unit weight of soil $\left(\gamma_{s}\right)$ & $1850 \mathrm{~kg} / \mathrm{m}^{3}$ \\
Unit weight of concrete $\left(\gamma_{c}\right)$ & $2400 \mathrm{~kg} / \mathrm{m}^{3}$ \\
Vertical acceleration coefficient $\left(k_{v}\right)$ & 0 \\
Horizontal acceleration coefficient $\left(k_{h}\right)$ & 0.3 \\
Maximum acceleration coefficient $\left(k_{\text {max }}\right)$ & 0.6 \\
Peak ground acceleration $($ PGA) & 0.6 \\
Peak ground velocity $($ PGV $)$ & $109.2 \mathrm{~cm} / \mathrm{s}$ \\
Site factor $\left(F_{p g a}\right)$ & 1 \\
Bearing resistance factor $\left(\varphi_{b}\right)$ & 0.8 \\
\hline & \\
&
\end{tabular}

Table 4 Allowable ranges of the design variables

\begin{tabular}{lcc}
\hline Design variable & Allowable range & Unit \\
\hline$w_{\text {bottom }}$ & {$\left[w_{\text {top }}+0.02 \times h_{\text {stem }}: 0.05: 3\right]^{*}$} & $\mathrm{~m}$ \\
$h_{\text {slab }}$ & {$[0.6: 0.05: 3]$} & $\mathrm{m}$ \\
$w_{\text {heel }}$ & {$[0: 0.05: 5]$} & $\mathrm{m}$ \\
$w_{\text {toe }}$ & {$[0: 0.05: 5]$} & $\mathrm{m}$ \\
$h_{\text {key }}$ & {$[0: 0.05: 2]$} & $\mathrm{m}$ \\
$w_{\text {key }}$ & {$[0: 0.05: 2]$} & $\mathrm{m}$ \\
$b_{\text {key }}$ & {$\left[0: 0.05: w_{\text {heel }}+w_{\text {bottom }}+w_{\text {toe }}-w_{\text {key }}\right]$} & $\mathrm{m}$ \\
$f_{c}($ stem $)$ & $\{20,25,30,35,40\}$ & $\mathrm{MPa}$ \\
$f_{c}($ slab $)$ & $\{20,25,30,35,40\}$ & $\mathrm{MPa}$ \\
\hline
\end{tabular}

* Generates numbers from the lower to the upper bound with a constant step size (the middle number).

In this example, the entire search takes place in a discrete decision space. The allowable ranges of the nine design variables, and the corresponding lower and upper bounds are summarized in Table 4 . In the optimization procedure, regarding constructability issues, if the depth of a shear key is obtained to be lower than $0.5 \mathrm{~m}$, the shear key is omitted, and all design variables related to the shear key are assumed to be zero. Similarly, if the length of a heel or a toe slab goes below $1.0 \mathrm{~m}$, that part of the base slab is omitted.

Due to stochastic nature of the NSGA-II algorithm, the program was run four times. The generated Pareto fronts are shown in Fig. 3(a), which displays a trade-off between permanent displacement and construction cost. Each Pareto front demonstrates the front number 1 solutions found in the last generation of the main procedure for a given run of the program. A magnified view is displayed in Fig. 3 (b) in order to provide an easier graphical comparison between the four Pareto fronts.

In all runs, a population of 500 individuals was evolved for 250 generations. The program consumed, on average, 3.8 hours to solve this optimization problem, using an Intel ${ }^{\circledR}$ Core $^{\mathrm{TM}}$ i7@2.0 GHz processor equipped with 8 GBs of RAM.

In order to compare the properties of different optimal solutions obtained in the four Pareto fronts, two particular solutions are investigated. These solutions are the extreme points correspond to the minimum construction cost (Solution A) and the minimum permanent displacement (Solution B). The properties of these two solutions are provided in Table 5. As reported in this Table, while the construction cost of Solution B is increased by $163.8 \%$ in comparison to Solution A, the corresponding permanent displacement is decreased by $82.5 \%$. 


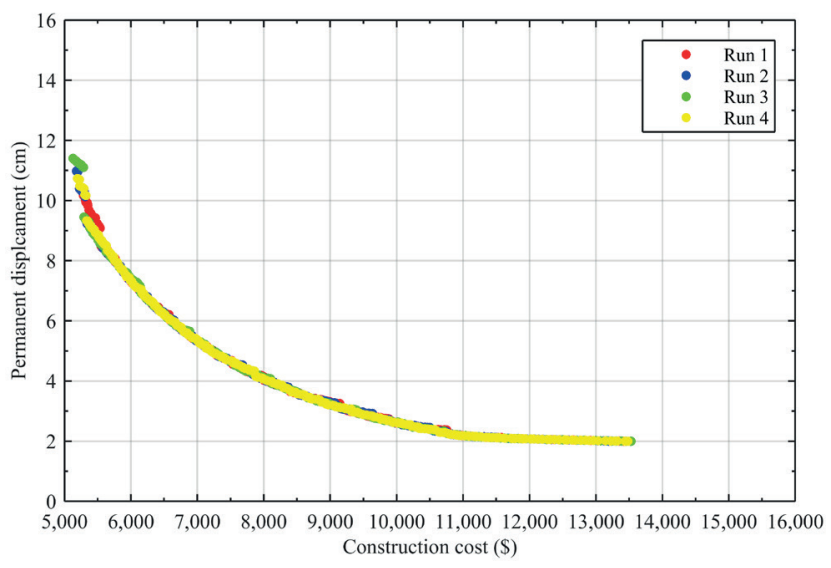

(a) Full view

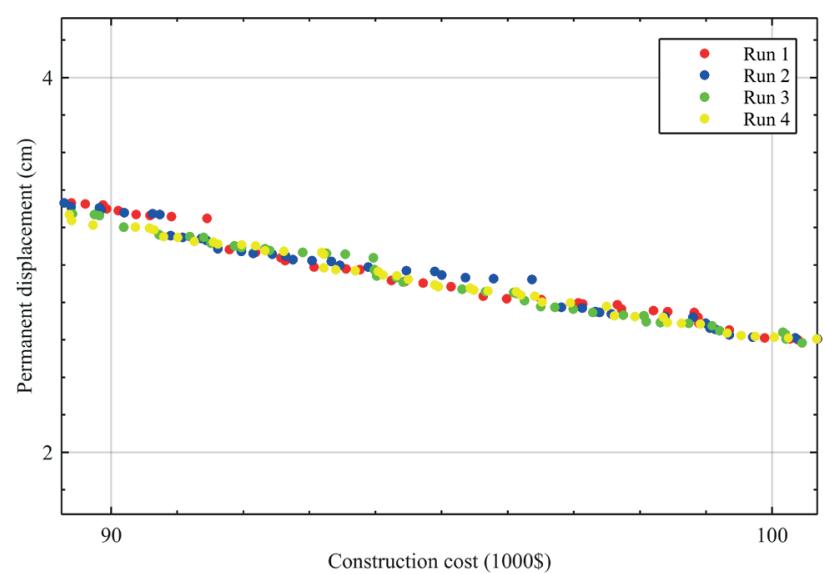

(b) Magnified view

Fig. 3 Generated Pareto fronts for case I

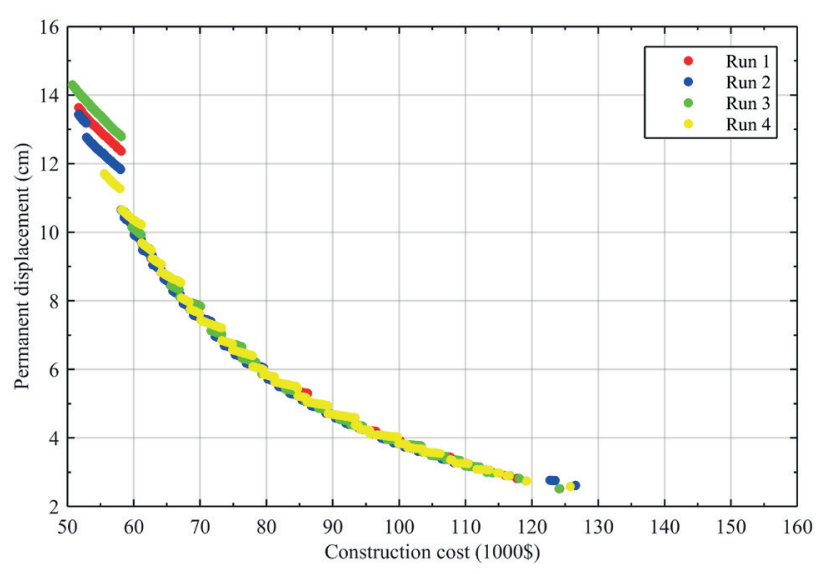

(a) Case II

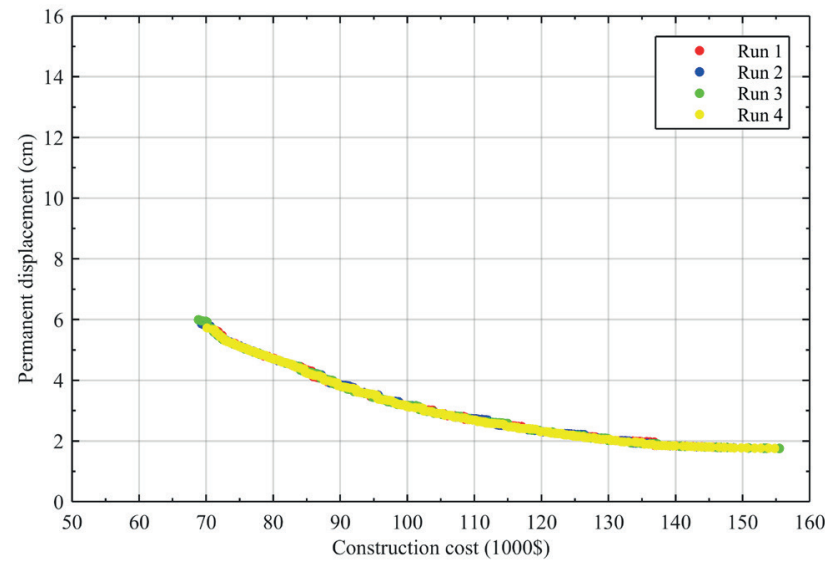

(b) Case II

Fig. 4 Generated Pareto fronts for cases II and III

\subsection{Case II: a wall without a heel slab}

In this case, the design of the test structure is repeated with no heel slab at the base. In order to provide enough length for the base, the maximum length of the toe is increased to 10 meters. Except the constraint of the base slab, all the constraints are the same as case I.

The generated Pareto fronts are shown in Fig. 4(a). Properties of two extreme Pareto optimal solutions correspond to the minimum construction cost (Solution C) and the minimum permanent displacement (Solution D) are listed in Table 6. Based on Table 6, the construction cost of Solution D is $144.7 \%$ higher than Solution C, while the permanent displacement is $82.4 \%$ lower.

\subsection{Case III: a wall without a toe slab}

In this case, the design of the test structure is repeated with no toe slab at the base. Similar to case II, all the constraints are the same as case I, except that the maximum length of the heel is increased to 10 meters.
Fig. 4(b) demonstrates the generated Pareto fronts. Properties of two extreme Pareto optimal solutions correspond to the minimum construction cost (Solution E) and the minimum permanent displacement (Solution F) are listed in Table 7. Based on Table 7, the construction cost of Solution $\mathrm{F}$ is $75 \%$ higher than Solution E, while the permanent displacement is $70.6 \%$ lower.

Fig. 5 displays the dimensions and schematic view of the optimal designs represented by Solution A and B for case I, Solution C and D for case II, and Solution E and F for case III.

\subsection{Discussion}

The number of Pareto optimal solutions, which form the four Pareto fronts in Fig. 3(a), Fig. 4(a) and Fig. 4(b), is 500 solutions in each figure. To help owners select a solution that satisfies seismic expectations and keeps within the budget, the performance level of each solution should be identified. In Fig. 6, Pareto optimal solutions are shown in two different colors according to their performance levels 
Table 5 Properties of Solution A and Solution B for case I

\begin{tabular}{|c|c|c|c|c|c|c|c|c|c|c|c|}
\hline \multicolumn{4}{|c|}{ Optimal design } & \multicolumn{8}{|c|}{ Reinforcement configuration } \\
\hline no. & $\begin{array}{c}\text { Design } \\
\text { variable }\end{array}$ & Solution A & Solution B & no. & $\begin{array}{l}\text { Diameter } \\
\text { Spacing }\end{array}$ & Solution A & Solution B & no. & $\begin{array}{l}\text { Diameter } \\
\text { Spacing }\end{array}$ & Solution A & Solution B \\
\hline 1 & $w_{\text {bottom }}$ & 0.76 & 0.71 & 1 & $D_{1}, S_{1}$ & Ø16@30 & Ø16@30 & 10 & $D_{10}, S_{5}$ & Ø16@30 & Ø28@15 \\
\hline 2 & $h_{\text {slab }}$ & 0.60 & 3.00 & 2 & $D_{2}, S_{1}$ & Ø16@30 & Ø16@15 & 11 & $D_{11}, S_{6}$ & Ø16@7.5 & Ø28@15 \\
\hline 3 & $w_{\text {heel }}$ & 2.35 & 5.00 & 3 & $D_{3}, S_{1}$ & Ø16@15 & Ø20@15 & 12 & $D_{12}, S_{6}$ & Ø16@30 & Ø28@15 \\
\hline 4 & $w_{t o e}$ & 3.80 & 5.00 & 4 & $D_{4}, S_{2}$ & 8Ø8@15 & 9Ø8@15 & 13 & $D_{13}, S_{7}$ & 5Ø8@15 & 5Ø10@15 \\
\hline 5 & $h_{k e y}$ & 2.00 & 2.00 & 5 & $D_{5}, S_{3}$ & Ø16@15 & Ø16@15 & 14 & $D_{14}, S_{8}$ & Ø12@30 & Ø12@30 \\
\hline 6 & $w_{k e y}$ & 0.50 & 2.00 & 6 & $D_{6}, S_{3}$ & Ø16@30 & Ø16@30 & 15 & $D_{15}, S_{9}$ & Ø16@30 & Ø25@15 \\
\hline 7 & $b_{k e y}$ & 6.40 & 2.35 & 7 & $D_{7}, S_{4}$ & Ø20@15 & Ø20@15 & & & & \\
\hline 8 & $f_{c}($ stem $)$ & 25 & 35 & 8 & $D_{8}, S_{4}$ & Ø18@15 & Ø12@25 & & & & \\
\hline \multirow[t]{3}{*}{9} & $f_{c}($ slab $)$ & 25 & 30 & 9 & $D_{9}, S_{5}$ & Ø20@15 & Ø28@15 & & & & \\
\hline & & & \multicolumn{9}{|c|}{ Objective function evaluation } \\
\hline & & & \multicolumn{3}{|c|}{ Construction cost } & \multicolumn{3}{|c|}{ Permanent diplacement } & \multicolumn{3}{|c|}{ Performance level } \\
\hline \multicolumn{3}{|c|}{ Solution A } & \multicolumn{3}{|c|}{$51293 \$$} & \multicolumn{3}{|c|}{$11.40 \mathrm{~cm}$} & \multicolumn{3}{|c|}{ High-risk } \\
\hline \multicolumn{3}{|c|}{ Solution B } & \multicolumn{3}{|c|}{$135300 \$$} & \multicolumn{3}{|c|}{$1.99 \mathrm{~cm}$} & \multicolumn{3}{|c|}{ Low-risk } \\
\hline
\end{tabular}

Units are the same as Table 4.

Both diameters and spacings are in $\mathrm{mm}$.

Table 6 Properties of Solution C and Solution D for case II

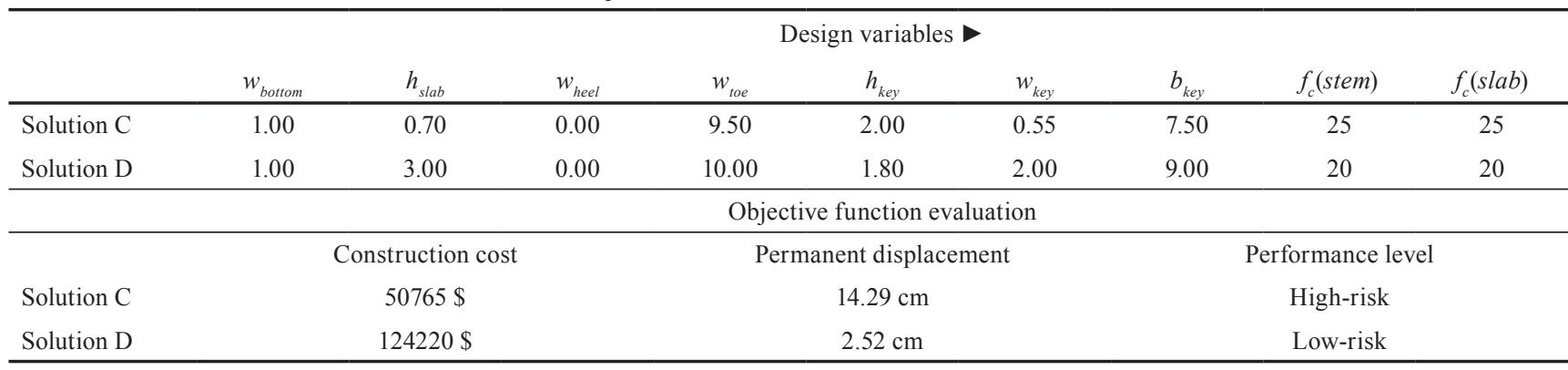

Units are the same as Table 4

Table 7 Properties of Solution E and Solution F for case III

\begin{tabular}{|c|c|c|c|c|c|c|c|c|c|}
\hline & \multicolumn{9}{|c|}{ Design variables } \\
\hline & $w_{\text {bottom }}$ & $h_{\text {slab }}$ & $w_{\text {heel }}$ & $w_{\text {toe }}$ & $h_{k e y}$ & $w_{k e y}$ & $b_{k e y}$ & $f_{c}($ stem $)$ & $f_{c}(s l a b)$ \\
\hline Solution E & 0.76 & 0.60 & 7.00 & 0.00 & 2.00 & 2.00 & 7.10 & 25 & 25 \\
\hline \multirow[t]{3}{*}{ Solution F } & 0.71 & 3.00 & 10.00 & 0.00 & 1.95 & 0.50 & 7.25 & 30 & 35 \\
\hline & \multicolumn{9}{|c|}{ Objective function evaluation } \\
\hline & \multicolumn{3}{|c|}{ Construction cost } & \multicolumn{3}{|c|}{ Permanent diplacement } & \multicolumn{3}{|c|}{ Performance level } \\
\hline Solution E & \multicolumn{3}{|c|}{$88867 \$$} & \multicolumn{3}{|c|}{$5.99 \mathrm{~cm}$} & \multicolumn{3}{|c|}{ High-risk } \\
\hline Solution F & \multicolumn{3}{|c|}{$155480 \$$} & \multicolumn{3}{|c|}{$1.76 \mathrm{~cm}$} & \multicolumn{3}{|c|}{ Low-risk } \\
\hline
\end{tabular}

Units are the same as Table 4.

for cases I, II and III. Solutions that have permanent displacements in the acceptable range are classified as "lowrisk" solutions, and they are shown in green; and solutions beyond that range, as "high-risk" solutions, in yellow. For instance, if the wall is located in the countryside, where large amounts of damage from the permanent movement are acceptable, it is recommended that owners select a yellow solution with a minimal construction cost. On the other hand, if the wall is located in a heavily traveled urban area, where it is very important to limit displacement to levels that will have negligible disruption to service, it is better to select a green solution with a minimal permanent displacement. In cases between these two extreme situations, the decision should be made taking into consideration the required amount of capital investment and the risk that the wall could pose to the traffic safety. 


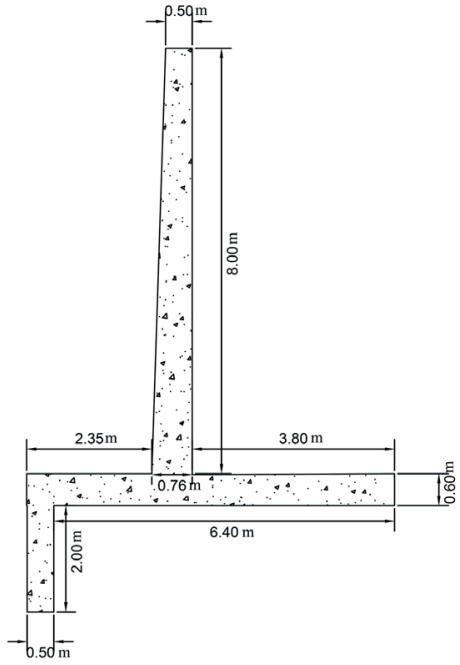

(a) Solution A

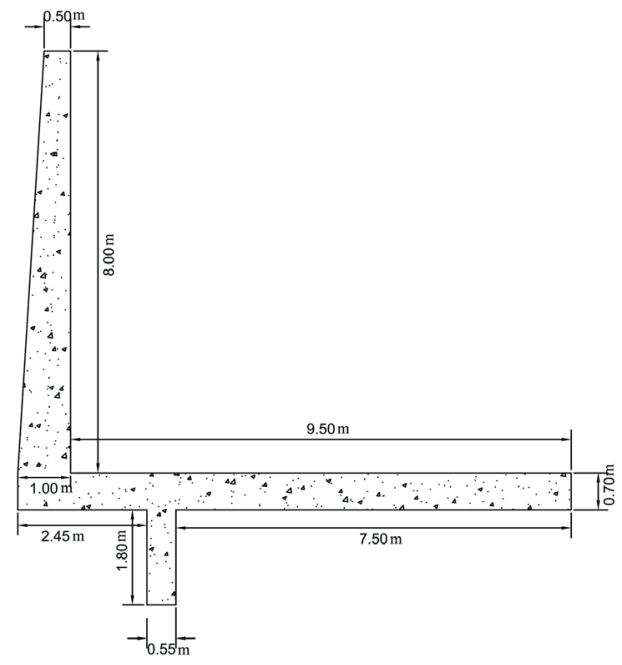

(c) Solution $\mathrm{C}$

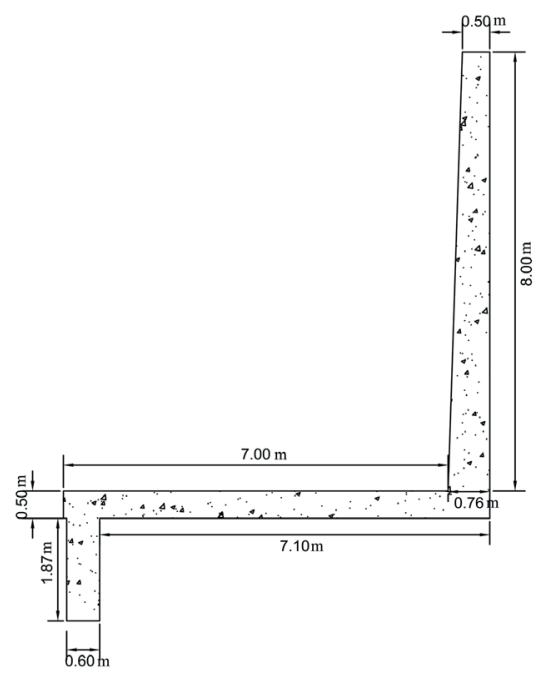

(e) Solution E

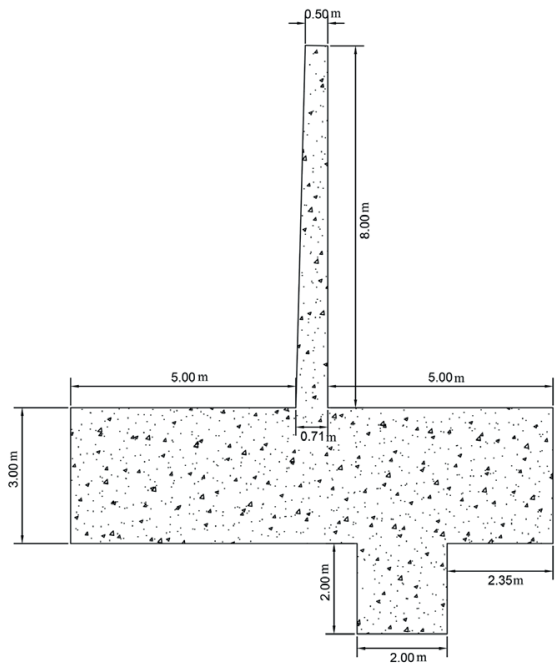

(b) Solution B

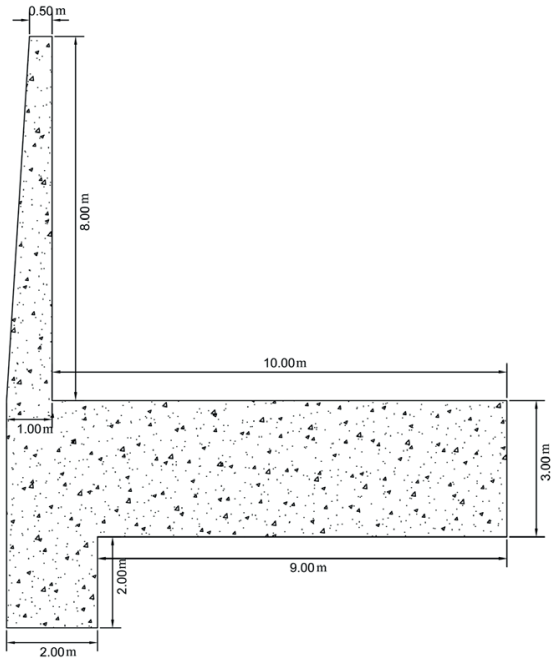

(d) Solution D

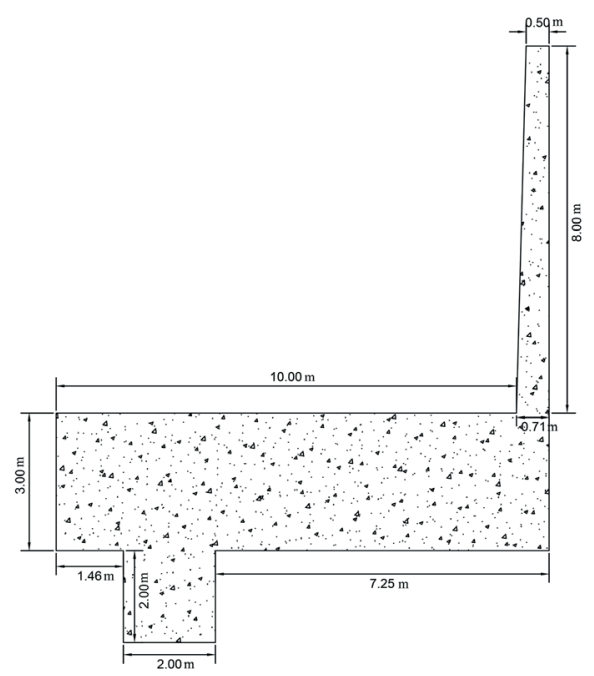

(f) Solution F

Fig. 5 Construction plans for cases I, II and III 


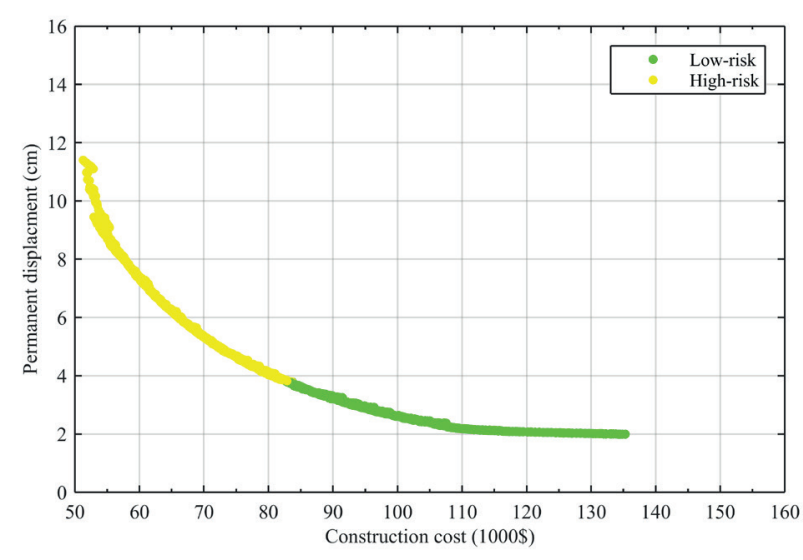

(a) Case I

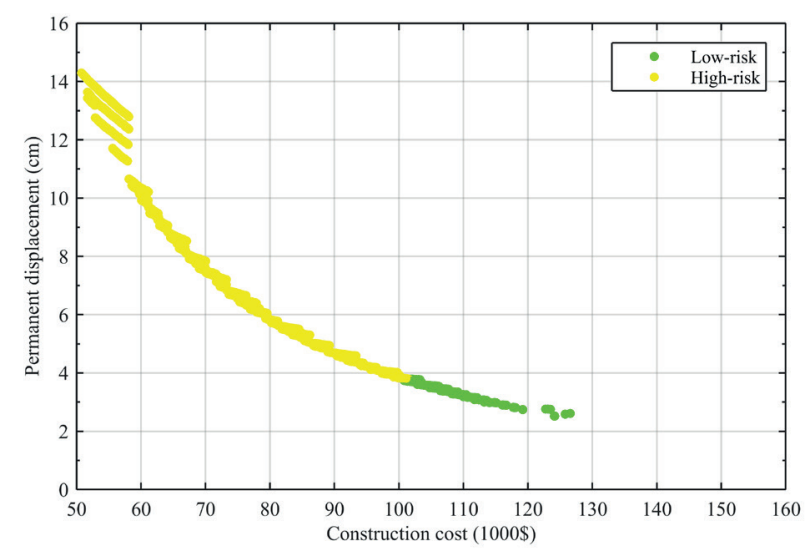

(b) Case II

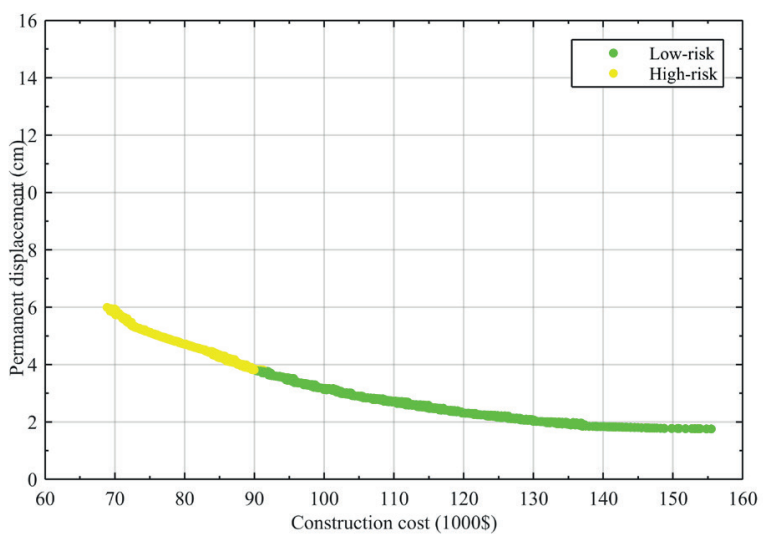

(c) Case III

Fig. 6 Performance level of Pareto optimal solutions for cases I, II and III

\section{Conclusions}

This study used the NSGA-II algorithm to extend the concept of performance-based design to retaining wall structures. A framework was proposed, in accordance with the seismic provisions of NCHRP-611, in which minimization of the construction cost and the permanent displacement of cantilever retaining walls were investigated as two separate objectives of the optimization problem. Obtaining
Pareto fronts of optimal solutions for these objectives, provides valuable information that helps owners or insurance companies to make the best decisions. Among the Pareto optimal solutions, they can select the one that is the most economical in trade-offs between financial burdens and seismic performance expectations. In this study, we have tried to follow most of the relevant constraints specified in the guidelines, so that the results may be useful for structural engineers in real-life projects.

Two performance levels were established for the seismic evaluation of cantilever retaining walls: low-risk and highrisk performance level. If the permanent displacement of a wall is calculated to be in the acceptable range, the wall is supposed to achieve the low-risk performance level; otherwise, the performance is at the high-risk level. The lowrisk level anticipates a very light damage. The force resisting system of the wall retains most of its pre-earthquake strength and stiffness. Some disruption to normal operation may be expected; however, the wall remains functional. At the high-risk level, damage may range from moderate to extensive. Strength and stiffness of the wall may be reduced but still provide a margin of safety against collapse. Significant disruption to service is possible.

A computer program was developed based on the proposed framework and operated for the design of a cantilever retaining wall of 8 meters in height. This problem was investigated in three different cases; firstly with both a toe and heel slab, secondly without a heel slab, and thirdly without a toe slab. For each case, four Pareto fronts made up of totally 1500 Pareto optimal solutions were obtained. Then, for each case, the properties of two extreme solutions located at the left and right end of the fronts were investigated in details and their construction plans were prepared. Uniform distribution of the Pareto optimal solutions and strong convergence, demonstrate that by using the proposed framework, convenient Pareto fronts of possible optimal solutions could be obtained.

\section{References}

[1] Das, B.M. "Principles of Foundation Engineering", 8th ed., Cengage Learning, Boston, USA, 2016.

[2] Saribas, A., Erbatur, F. "Optimization and sensitivity of retaining structures", Journal Geotechnical Engineering, 122(8), pp. 649-656, 1996.

https://doi.org/10.1061/(ASCE)0733-9410(1996)122:8(649)

[3] Ceranic, B., Fryer, C., Baines, R.W. "An application of simulated annealing to optimum design of reinforced concrete retaining structures", Computers \& Structures, 79(17), pp. 1569-1581, 2001. https://doi.org/10.1016/S0045-7949(01)00037-2 
[4] Yepes, V., Alcala, J., Perea, C., González-Vidosa, F. "A parametric study of optimum earth-retaining walls by simulated annealing", Engineering Structures, 30(3), pp. 821-830, 2008.

https://doi.org/10.1016/j.engstruct.2007.05.023

[5] Ahmadi-Nedushan, B., Varaee, H. "Optimal design of reinforced concrete retaining walls using a swarm intelligence technique", presented at Proceedings of the First International Conference on Soft Computing Technology in Civil, Structural and Environmental Engineering, Madeira, Portugal, Sept. 1-4, 2009.

https://doi.org/10.4203/ccp.92.26

[6] Kaveh, A., Shakouri Mahmud Abadi, A. "Harmony search based algorithm for the optimum cost design of reinforced concrete cantilever retaining walls", International Journal of Civil Engineering, 1(9), pp. 1-10, 2011. [online] Available at: http://ijce.iust.ac.ir/article-1-292-en.pdf [Accessed: 02.04.2019]

[7] Camp, C. V., Akin, A. "Design of Retaining Walls Using Big BangBig Crunch Optimization", Journal of Structural Engineering, 138(3), pp. 438-448, 2012.

https://doi.org/10.1061/(ASCE)ST.1943-541X.0000461

[8] Talatahari, S., Sheikholeslami, R. "Optimum design of gravity and reinforced retaining walls using enhanced charged system search algorithm", KSCE Journal of Civil Engineering, 18(5), pp. 14641469, 2014.

https://doi.org/10.1007/s12205-014-0406-5

[9] Kaveh, A., Soleimani, N. "CBO and DPSO for optimum design of reinforced concrete cantilever retaining walls", Asian Journal of Civil Engineering, 16(6), pp. 751-774, 2015. [online] Available at: https:// ajce.bhrc.ac.ir/Portals/25/PropertyAgent/2905/Files/5784/751.pdf [Accessed: 02.04.2019]

[10] Kaveh, A., Farhoudi, N. "Dolphin echolocation optimization for design of cantilever retaining walls", Asian Journal of civil Engineering, 17(2), pp. 193-211, 2016. [online] Available at: https:// ajce.bhrc.ac.ir/Portals/25/PropertyAgent/2905/Files/6842/193.pdf [Accessed: 02.04.2019]

[11] Kaveh, A., Kalateh-Ahani, M., Fahimi-Farzam, M. "Constructability optimal design of reinforced concrete retaining walls using a multi-objective genetic algorithm", Structural Engineering and Mechanics, 47(2), pp. 227-245, 2013.

https://doi.org/10.12989/sem.2013.47.2.227

[12] ASCE "Prestandard and Commentary for the Seismic Rehabilitation of Buildings", Federal Emergency Management Agency, Washington, D.C., USA, Rep. FEMA 356, 2000. [online] Available at: https:// www.fema.gov/media-library-data/20130726-1444-20490-5925/ fema_356.pdf [Accessed: 02.04.2019]

[13] Lai, S. "Rigid and Flexible Retaining Walls During Kobe Earthquake", In: Proceedings of the Fourth International Conference on Case Histories in Geotechnical Engineering, St. Louis, Missouri, USA, 1998. pp. 108-127. [online] Available at: https://scholarsmine.mst.edu/cgi/viewcontent.cgi?article $=1838 \&$ context $=$ icchge [Accessed: 02.04.2019]

[14] Li, X., Wu, Y., He, S. "Seismic stability analysis of gravity retaining walls", Soil Dynamics and Earthquakes Engineering, 30(10), pp. 875-878, 2010.

https://doi.org/10.1016/j.soildyn.2010.04.005
[15] Transport Research Board "Seismic Analysis and Design of Retaining Walls, Buried Structures, Slopes, and Embankments", National Cooperative Highway Research Program, Washington, D.C., USA, Rep. 611, 2008. [online] Available at: http://www. ce.memphis.edu/7137/PDFs/Seismic\%20Manual/nchrp_rpt_611. pdf [Accessed: 02.04.2019]

[16] Talbi, E.-G. "Metaheuristics: From Design to Implementation", 1st ed., John Wiley \& Sons, New Jersey, USA, 2009. https://doi.org/10.1002/9780470496916

[17] Deb, K., Pratap, A., Agarwal, S., Agarwal, S., Meyarivan, T. "A fast and elitist multi-objective genetic algorithm: NSGA-II", IEEE Transactions on Evolutionary Computation, 6(2), pp. 182197, 2002. https://doi.org/10.1109/4235.996017

[18] Kaveh, A., Behnam, A. F. "Charged System Search Algorithm for the Optimum Cost Design of Reinforced Concrete Cantilever Retaining Walls", The Arabian Journal of Science and Engineering, 38(3), pp. 563-570, 2013.

https://doi.org/10.1007/s13369-012-0332-0

[19] ACI-318-14 "Building Code Requirements for Structural Concrete and Commentary", American Concrete Institute; Farmington Hills, MI, USA, 2014.

[20] AASHTO LRFD "Bridge Design Specification", 6th ed., American Association of State Highway and Transportation Officials", Washington, D.C., USA, 2012.

[21] NCHRP-12-70 "Seismic Analysis and Design of Retaining Walls Buried Structures Slopes and Embankments: Recommended Specifications Commentaries and Example Problems", National Cooperative Highway Research Program, Washington, D.C., USA, Draft Final Report, 2008.

[22] Munfakh, G., Arman, A., Collin, J. G., Hung, J. C.-J., Brouillette, R. P. "Shallow Foundations Reference Manual", FHWA-NHI-01-023, Federal Highway Administration, U.S. Department of Transportation, Washington, D.C., USA, 2001.

[23] Deb, K. "Multi-Objective Optimization using Evolutionary Algorithms", 1st ed., Wiley, New York, USA, 2009.

[24] Coello, C. A. C., Pulido, G. T., Lechuga, M. S. "Handling multiple objectives with particle swarm optimization", IEEE Transactions on Evolutionary Computation, 8(3), pp, 256-279, 2004. https://doi.org/10.1109/TEVC.2004.826067

[25] MathWorks "The Language of Technical Computing", The MathWorks Inc., Natick, Massachusetts, United States, [online] Available at: 2014. https://www.mathworks.com/products/matlab. html [Accessed: 02.04.2019]

[26] Earthquake Hazards Program "U.S. Seismic Design Maps", United States Geological Survey (USGS), Virginia, USA, 2018. [online] Available at: https://earthquake.usgs.gov/hazards/designmaps/ usdesign.php [Accessed: 02.04.2019] 